\title{
APONTAMENTOS SOBRE O(S) MODO(S) DE FORMAÇÃO DE ATORES, EM FOCO: LEOPOLDO FRÓIS
}

\author{
Narciso Telles ${ }^{1}$
}

\section{Resumo}

$\mathrm{O}$ presente artigo tece alguns apontamentos em torno do modo de formação do ator Leopoldo Fróis no decorrer de sua trajetória artística e sua relação com um modo de produção teatral popular que, neste caso, esteve vinculado às chamadas 'comédias de costumes' as quais possuíam características próprias em sua estrutura dramatúrgica e cênica. Verificamos que o exercício atorial de Leopoldo foi constante dentro de um teatro dito de diversão e que este ator soube apreender e aprimorar acervos técnicosquegarantiriamumaidentificação maior com seu público, somado aos seus possíveis 'dotes pessoais', conforme assinalam alguns analistas do período.

Palavras-chave: Leopoldo Fróis, comédias de costumes, exercício atorial.

\begin{abstract}
The present article weaves some notes around the way of actor's Leopoldo Fróis formation in elapsing of your artistic path and your relationship with a way of popular theatrical production that, in this case, it was linked to the calls comedies of habits, which possessed own characteristics in your structure dramatúrgica and scenic. We verified that the exercise atorial of Leopoldo was constant inside of a said theater of amusement and that this actor knew how to apprehend and to perfect technical collections thatwould guarantee a larger identification with your public, added your possible personal dotes, as they mark some analysts of the period.
\end{abstract}

Keywords: Leopoldo Fróis, comedies of habits, exercise atorial.

A historiografia do teatro brasileiro nos últimos anos tem, em grande parte pelo crescimento dos Programas de Pós-Graduação em Teatro/Artes/ Artes Cênicas, retomado temas e questões num gradativo processo de revisão da escrita e do olhar sobre a história de nossa produção teatral, em especial, dos cânones que conduziram a pesquisa até então. Neste movimento a comediografia carioca vem gradativamente ocupando um local de excelência. Considerada um gênero menor, inserida no chamado teatro-digestivo ou teatro de diversão foi quase sempre relegada ao obscurantismo acadêmico, sem merecer o aprofundamento analítico necessário.

\footnotetext{
${ }^{1}$ Ator, professor do Curso de Teatro e do Programa de Pós-Graduação em Artes da Universidade Federal de Uberlândia (UFU). Membro do Coletivo Teatro da Margem. [narcisotelles@ hotmail.com_
} 
2 RABETTI, Beti. Subsídios para a história do ator no Brasil: pontuações em torno do lugar ocupado pelo modo de interpretar de Dulcina de Moraes entre tradição popular e projeto moderno. Revista do LUME, n. 02, UNICAMP/COCEN. Campinas, 1999, p. 45.

Aqui, procuramos contribuir com esta revisão focando nosso olhar para o(s) modo(s) de formação do ator, tendo como exemplo um dos principais atores brasileiros do período: Leopoldo Fróis. Este olhar pontual pretende relacionar o universo textual-dramatúrgico da chamada 'comédias de costumes' com os procedimentos de formação/atuação de Fróis

numa cena em que a presença é determinada substancialmente por seu próprio virtuosismo e por seu intenso contato com o público consumidor de uma arte teatral que então empreende suas tentativas para arrematar um mercado em temporária expansão.

Cabe mencionar que o trabalho de re-construção ou a busca de indícios do que poderia ter sido o modo de formação/interpretação de Fróis neste trabalho tem seu eixo de análise no escrito de memorialistas e críticas jornalísticas. Estas últimas encontradas na pasta do ator localizada na Centro de Documentação da FUNARTE - Rio de Janeiro.

\section{O teatro carioca ligeiro dos anos 20: um modo de produção artística popular}

A cidade do Rio de Janeiro na primeira metade do século XX caminha em direção a Paris. A reforma urbana do Prefeito Pereira Passos modifica a paisagem da capital federal ancorada no discurso da modernidade - que era então o modelo parisiense - contra a barbárie da tradição colonial. A cidade que deseja ter um modelo de comportamento europeu nos trópicos valoriza as produções culturais, diga-se de passagem, da cultura letrada.

É nesta urbi carioca que é construído em 1915 o Teatro Trianon, edifício teatral que marcará toda uma geração de autores, atores e empresários teatrais ligados, em sua maioria, ao teatro de diversão. Este edifício teatral possuía platéia, galeria, balcão nobre, balcão simples e fosso de orquestra. Tal arquitetura cênica abrigava o teatro ligeiro que possuía um modo de produção teatral popular que abarcava algumas características fundamentais que marcam esta forma de fazer teatral.

$\mathrm{Na}$ 'máquina' de fazer teatro ligeiro, onde a cada semana um novo espetáculo deveria ser colocado em cartaz. As companhias viviam constantemente em ensaio para um novo espetáculo assim que o anterior era estreado. A movimentação desta engrenagem estava entregue nas mãos de ensaiadores, aos quais cabia

marcar o espetáculo. Cuidava também dos objetos de cena, dos horários dos atores, mas como tarefas adicionais. $\mathrm{O}$ bom 


\section{Urdimento}

ensaiador era aquele que, no menor prazo de tempo, articulava os atores de modo que não se embarrassem e tornassem a cena compreensível ${ }^{3}$.

Maria Filomena Chiaradia em seu estudo sobre a Companhia de Revistas e Burletas do teatro São José apresenta-nos algumas características presentes neste tipo de organização teatral comum no teatro carioca do período e, "asseguradora de sobrevivência e aprendizagem para parte significativa da classe teatral carioca ${ }^{4 ”}(60)$.

As companhias estavam organizadas, na sua maioria, por atoresempresários que conduziam tanto a cena - na função dos primeiros atores - quanto à administração da companhia. Tais companhias eram estruturadas a partir do recurso de variar o elenco, ou seja, uma gama grande de atores eram acionados a cada montagem, permitindo uma intensa movimentação dos atores a procura de um elenco onde pudessem se integrar.

Como forma de ampliar o alcance do espetáculo teatral ao gosto do público é criado o sistema de teatro por sessões. Chiaradia aponta dois aspectos importantes para a implantação do teatro por sessões nas companhias dedicadas ao teatro popular "de diversão": "1 - a construção/ criação da peça teatral em função de três sessões diárias; 2 - a aproximação dos espetáculos teatrais a contexto, ainda embrionário nesse período, de cultura de massa, de indústria cultural ${ }^{5}$.

Este sistema de teatro por sessões utilizado por diversos gêneros do teatro ligeiro elucida um conjunto de características determinantes de todo um conjunto dramatúrgico das primeiras décadas do século XX que deverá necessariamente prende-se as exigências da cena e não mais da literatura. Configurando um modo de fazer teatral no qual os autores necessitariam de uma especialização, "isto é, da exigência de domínio técnico diferenciado para criar textos adequados a um novo tipo de produção cênica; o esgotamento físico e artístico dos artistas, gerado pelo estabelecimento de rotina de trabalho (intenso e sem folga semanal); a necessidade de atender à demanda crescente de produções; a tentativa, nos melhores casos, de manter, ao mesmo tempo, qualidade artística e interesse do público.

A própria dinâmica deste processo de produção teatral determinava a existência do ponto que ficava sob o palco era o único que possuía todo o texto - os atores recebiam apenas sua parte e a deixa - este aparecia para os atores, mas permanecia escondido do público por uma caixa de madeira localizada no procênio e vazada na frente. O ponto dizia as falas seguintes a cada pausa dos atores.
${ }^{3}$ TROTTA, Rosyane. 0 teatro brasileiro: décadas de $1920-30$. In BRANDÃO, Tânia (org.) 0 Teatro através da história. Rio de Janeiro: CCBB/Entourage, 1994. p. 115

${ }^{4}$ CHIARADIA,

Maria Filomena $\mathrm{V}$. A Companhia de

Revistas e Burletas do Teatro São José: a menina-dos-olhos de Paschoal Segreto.

Dissertação

(Mestrado em

Teatro). CLA-UNIRIO, Rio de Janeiro, 1997, p. 60.

${ }^{5}$ CHIARADIA, op. cit., p. 154. 


\section{Urdimento}

${ }^{6}$ RABETTI, Beti. História do teatro "popular" no Brasil: Gastão Tojeiro entre autoria artística e práticas sociais do teatro ligeiro. Revista do LUME, n. 06, UNICAMP/COCEN. Campinas, 2005, p. 140.

\footnotetext{
${ }^{7}$ RABETTI, Beti. 0 "homem de teatro" Armando Gonzaga: entre comédias de costume e um costume de fazer comédias. OuvirOuver, n. 01, 2005. DEMAC/UFU. Uberlândia, 2005, p. 32.
}

Uma outra característica do teatro ligeiro eram os personagenstipos. A escrita dramatúrgica e cênica destes espetáculos eram calcados na tipificação dos papéis, onde os atores se encaixariam, segundo seu perfil, ocupando uma determinada função na peça.

No modo de produção popular do teatro ligeiro, o que determinava a qualidade e a permanência do espetáculo era o gosto do público, melhor dizendo, a bilheteria. Desta forma teremos, também, uma dramaturgia integrada a este modo de produção teatral - com características próprias de atendimento a incipiente indústria do divertimento que se instala na cidade do Rio de Janeiro neste momento.

\section{Aspectos da dramaturgia de Gastão Tojeiro e Armando Gonzaga}

Do conjunto de autores da chamada Geração Trianon, ou seja, autores que se dedicaram inteiramente, ou mesmo parcialmente, a prática dramatúrgica destinada ao teatro ligeiro, de diversão, as conhecidas comédias de costumes, podemos considerar Gastão Tojeiro e Armando Gonzaga como dois dos mais significativos.

Ambos dominavam os mecanismos próprios deste modo de produção teatral, de forma a operarem "sucessivos ajustes de sua própria obra mediante os limites do palco, do ator, do empresário e do público, procedendo a adaptações, a sínteses e atualizações de repertórios tradicionais dramatúrgicos ${ }^{6}$.

Rabetti afirma, com base em levantamento realizado em arquivos cariocas, que Armando Gonzaga, por exemplo, possui aproximadamente 90 "peças kodac", que vão muito além de um retrato dos costumes,

são preciosos indicadores de um modo concreto de viver do teatro e produzir dramaturgia e cena absolutamente característicos do "teatro ligeiro": mais preocupado em divertir casas cheias, que retratar realisticamente pessoas e costumes de época, fazendo de seus textos cômicos, segundo muitos, documentos literais de um determinado periodo de nossa história republicana. ${ }^{7}$

Nesta mesma linha segue Gastão Tojeiro, autor de diversas comédias de sucesso como: Onde canta o sabiá, $O$ simpático Jeremias, $A$ inquilina de Botafogo, O Felisberto do café entre outras.

Sábato Magaldi ao analisar a dramaturgia do período identifica como característica principal: 


\section{Urdimento}

permitir que os primeiros atores, de se tornarem ídolos populares, dispusessem de um esboço sobre o qual pudessem projetar sua personalidade. [...] A improvisação de efeitos cômicos, a gosto dos cacos, o desequilíbrio do conjunto, não organizado em verdadeira equipe, contribuíram para situar sempre em primeiro plano a figura do astro, senhor absoluto do palco ${ }^{8}$.

Aqui, preferimos identificar esta escrita dramatúrgica inserida num modo de produção artística popular que lhe dava contornos próprios, inclusive a possibilidade de que os atores pudessem trafegar com liberdade em seu interior, elemento este, presente na tradição cômica ocidental. Além de promover parcerias entre autores e atores, nas quais os primeiros escreviam sob encomenda para as companhias, como no caso da parceria de sucesso entre Leopoldo Fróis e Gastão Tojeiro.

Nesta dramaturgia um dos aspectos fundamentais era a movência dos textos, onde havia "uma liberdade de se alterar o texto segundo as necessidades cênicas que se apresentavam no momento dos ensaios. A própria construção do texto permite procedimentos de exclusão e inclusão sem alterar ou promover mudanças significativas em seu fio condutor. Estes procedimentos são verificados em diversos gêneros do teatro ligeiro, como “as burletas aproximam-se mais da comédia de costumes, visto que também privilegiam mais o enredo de ficção do que a crônica do cotidiano do país ou da cidade, tão importante para a revista" ${ }^{9}$.

Enredo das comédias de costumes: o homem em sociedade, onde os ${ }^{8}$ MAGALDI, Sábato.
Panorama do Teatro
Brasileiro. São Paulo:
Global, 1997. p. 195.

${ }^{9}$ CHIARADIA, op. cit., p. 75 . costumes da época, principalmente da burguesia, a organização social e política eram trazidos e satirizados no palco. As cenas vividas no cotidiano urbano eram reelaboradas de forma cômica, farsesca, porém sem uso de cenas vulgares ou apelativas. A sociedade era retratada pelas comédias de costumes através de personagens-tipos que representavam os habitantes populares da cidade.

Um dos maiores sucessos da Cia Leopoldo Fróis no Trianon foi $\mathrm{O}$ Simpático Jeremias de Gastão Tojeiro. Numa das primeiras cenas Jeremias, um aprendiz de filosofia, apresenta-se para trabalhar como criado na casa de Madalena, o autor utiliza-se de mecanismos de comicidade para a apresentação do personagem e sua linguagem retórica/filosófica. Vamos à cena:

$$
\begin{aligned}
& {[\ldots]} \\
& \text { Madalena }-E \text { é o senhor que pretende empregar-se como } \\
& \text { criado? }
\end{aligned}
$$

Violeta - Oh, ser muita interessante!

Madalena - (A Jeremias) Entre. Então o senhor.... 
${ }^{10}$ VELLOSO, Mônica Pimenta. A cultura das ruas no Rio de Janeiro (1900-30). Mediações, linguagens e espaços. Rio de Janeiro: Casa de Rui Barbosa, 2004. p. 59.
Jeremias - Sim minha senhora, venho fazer jus a uma parca soldada para a subsitência material do miserável invólucro do espírito. Sim, porque a alma essa alimento-a com a sã filosofia que me legou o meu excelso mestre, o venerável Sirênio Calado.

Madalena - Será um doido?

Violeta-Que filósofo foi esse?

Jeremias - Oh, um grande e imperecível filósofo! Viveu na obscuridade sublime dos espíritos superiores. Durante seis longos anos estive eu em sua companhia ouvindo-lhe, dia a dia, suas palavras sempre repassadas de grandes ensinamentos e de incomparável grandeza moral, transbordantes de elevados preceitos e imutáveis verdades sobre a vida humana. (Num gesto de evocação) Quanto te agradeço excelso mestre, que pairas nesse mundo invisivel para onde emigrou a tua alma privilegiada de filósofo, a sabedoria da vida que me legaste!

Madalena - O senhor é positivamente um louco! Pode ir embora, que não me serve para criado.

$[\cdots]$

No trecho acima é perceptível como o autor trabalha a tensão entre linguajares - o de um possível filósofo e seu falar erudito e a função que deseja ocupar o de criado, com sua fala popular. Inclusive é esta tensão que, desmembrada ao longo da peça provocará diversos momentos de comicidade. Cabe ressaltar que uma outra característica era à busca de uma língua predominantemente brasileira abandonando o uso do linguajar português. Este movimento em torno de uma língua brasileira é algo extremamente discutido no final do século XIX e nas primeiras décadas do século XX.

Mônica Velloso em seu estudo sobre a cultura popular urbana na cidade do Rio de Janeiro de 1900 a 1930 verifica que "o caráter conflituoso que reveste a invenção do idioma nacional está imbuído de uma negociação permanente entre a fala e a língua, buscando assegurar sua legitimidade ${ }^{10 "}$.

Cena 3 - Valquíria e Felisberto seu marido?...

FEL (rindo) - Como ele vai atrapalhado com a bandeja! É

$$
V A L-N \tilde{o} \text {. }
$$

FEL - Quer dizer então que é seu...o seu "pequeno"..

VAL - Assim tão grande? Não uso esses animais de luxo. É apenas o autor da peça "Pecadora arrependida", que vou representar. É um dramaturgo de talento!

FEL (rindo) - Dramaturgo de talento que nem sabe pegar numa bandeja....(Lembrando-se) É verdade! Estão a minha espera para ouvir o resto da conferência e eu aqui a dar à língua. 
$[\cdots]$

Do dramaturgo passa-se a brincar com a função da atriz:

$[\cdots]$

VAL - É isso mesmo! Onde tinha eu a cabeça...Sabe que sou atriz?

FEL - Sei. E chama-se Valquiria Deslisante.

VAL (admirada) - Já sabia meu nome?

FEL - Quem não a conhece? A senhora é mais conhecida do que a praia de Copacabana. Como a senhora representa bem!

$V A L$ - Se represento...Já me viu representar?

FEL - Vi... Naquela peça em que a senhora bancava a maluca rasgando toda a roupa e ficando só de tanga.

VAL (rindo) - De tanga? Que disparate! Ficava em combinação. Era uma combinação. Combinação é o nome daquela peça de roupa.

FEL - Como eu gostei da peça!

$V A L-D e$ que peça?

FEL - Da peça que a senhora representou...

VAL - Ah, sim... Era a "Louca de amor". Eu fazia bem aquela louca?

FEL - Para mim todas as mulheres vão sempre bem quando praticam loucuras de combinação.

$[\cdots]$

A cena acima citada da peça de Tojeiro, Felisberto do Café ou $A$ conferência do 'garçon', farsa em 01 ato encenada em 1931, convalida aspectos característicos desta dramaturgia: as falas com um 'duplo sentido', eficaz para provocar o riso na platéia; a inversão de valores, no caso do próprio teatro, onde as figuras de dramaturgo e atriz são alvo de brincadeiras e trocadilhos, percebe-se também a tensão mencionada antes entre o papel e a função. Um dramaturgo que não sabe segurar uma bandeja. Gostaria de destacar também o valor das reticências - que no trecho citado são várias. Podemos aventar a hipótese de que esses 'vazios de palavras' pudessem ser preenchidos pelos atores com gestualidade e cacos, que reforçassem a comicidade e mantivessem a cumplicidade com o público.

Se entendermos que as comédias de Tojeiro e Gonzaga estão inseridas neste modo de produção popular, no qual o público tem uma importância para sua existência, podemos concluir que as tensões existentes neste momento histórico serão muitas vezes mediadas por esta escrita dramatúrgica e proporcionará aos atores um 'locus' privilegiado de formação teatral. 


\section{Apontamentos sobre o(s) modo(s) de formação de atores, em foco: Leopoldo Fróis}

Nas primeiras décadas do século XX a formação atorial no Brasil se dava por três percursos: o ensino regular da Escola Dramática Municipal; pelo aprendizado familiar ou pela prática da cena.

A Escola Dramática Municipal fundada por Coelho Neto em 1908 é considerada a primeira escola de teatro do Brasil e da América Latina. Nela institui-se no Brasil a educação teatral formal, centrada em disciplinas com conteúdos específicos e complementares para a formação do intérprete. Dentre as disciplinas ministradas destaca-se: prosódia, arte de dizer, arte de representar, literatura dramática e história. É interessante perceber como a criação da escola está atrelada a um discurso da época evocando a necessidade de uma formação aos atores de forma que pudessem melhorar seu desempenho na cena.

Uma segunda via possível de formação de atorial seria pela família. Neste período era comum nas companhias teatrais à formação familiar. Muitos atores casavam-se durante as temporadas mambembes pelo Brasil. Filhos e filhas nasciam neste percurso e eram criados - muitas vezes - nas coxias e camarins dos teatros onde se apresentavam. Como exemplo, temos a atriz Dulcina de Moraes, filha dos atores Átila e Conchita de Moraes, teve seu aprendizado teatral iniciado pelo convívio com seus pais. Este mesmo princípio de aprendizado era comum nos circos brasileiros.

A família, portadora de saberes e práticas presentes na memória preservada de seus antepassados, fez parte de todas as fases de construção do circo no Brasil. Na virada do século consolida-se um "território" formado pelas várias famílias circenses, que apesar das mudanças tecnológicas e suas implicações internas, estruturam-se em torno da manutenção da transmissão oral daqueles saberes e práticas, de geração a geração. E é esta relação familiar que a torna responsável pela formação e capacitação de seus membros.

Como nos circos, a formação atorial familiar é responsável pelo aprendizado artístico inicial que vai sendo aprimorado no enfrentamento com o fazer teatral, ou seja, assimilando técnicas de interpretar pela vivência atorial em cada montagem e não, de um conjunto de conhecimentos formalizados a priori. Mesmo no caso dos atores que se especializavam em tipos, a testagem e a afinação deste aprendizado ocorre na cena diante do espectador.

Podemos ainda considerar uma terceira via de aprendizado, quando o ator não passa pelo ensino formal da escola de teatro e nem adquiri informações teatrais pela formação familiar. Neste caso é na prática atorial em diversos espetáculos que o ator vai aprimorando seu repertório técnico, este é o caso 
do ator Leopoldo Fróis, o mais famoso de seu tempo. O presente texto busca apresentar indícios sobre o modo de formação atorial deste ator e sua relação com o modo de produção teatral popular no teatro carioca nas primeiras décadas do século XX.

\section{Leopoldo Fróis e a formação pela prática atorial}

Leopoldo Fróis da Cruz nasceu em 30 de setembro de 1882 no município de Niterói. Filho de Luis Carlos Fróis da Cruz e Idalina Rodrigues Guimarães Fróis da Cruz. Estreou no teatro no Clube Dramático Assis Pacheco na peça "O Lobo e o Cordeiro". Formou-se em Direito, atividade que abandona - para desgosto do pai - quando viaja para Portugal, país este que inicia sua trajetória teatral.

Na busca de indícios da formação atorial de Leopoldo Fróis, encontramos no comentário de Alfredo Tomé uma primeira indicação sobre o aprendizado artístico em Portugal no ano de 1903:

De vila em vila, de cidade em cidade, Leopoldo Fróis foi se adestrando nos segredos da técnica de representar. Aqui, era uma emoção nova. Ali, uma impressão diferente. Acolá, um detalhe que the vinha encorpar experiência. Desdobrava-se-lhe o sentido da observação. Platéias bondosas e paternais. Com elas, Fróis despojava-se do acanhamento natural para ir adquirindo aquela soberba naturalidade tanto mérito lhe grangearia. Nessas excursões, a sua especialidade por assim dizer era genérica. Ora ator dramático, pronunciando as palavras com a voz gutural e metálica; ora ator cômico, bonachão e simplório, transbordando simpatia e a provocar gostosas gargalhadas; ora cançonetista, modulando a voz fresca a entoar modinhas brasileiras ${ }^{11}$.

Neste percebemos que o ator inicia seu processo de formação pela constante prática da cena e junto ao público, num movimento de testagem e verificação o interprete vai constituindo um acervo técnico específico.

Ainda em Portugal, Fróis trabalha com o ator e empresário português José Ricardo que, segundo Tomé, foi fundamental na formação atorial de Leopoldo.

[...] deste aprendeu o que desconhecia na arte de representar. Assimilou a essência dos gestos, das atitudes e das inflexões; observouthe as nuances da voz; admirou-lhe a plasticidade interpretativa e o processo de que se utilizava para transmitir as próprias emoções à platéia. O que mais remarcava [José] Ricardo era e elegância e a sobriedade com que se movimentava e contracenava no palco ${ }^{12}$.

${ }^{12}$ Idem, p. 107.

${ }^{11}$ TOMÉ, Alfredo. Leopoldo Fróis e o teatro brasileiro. Rio de Janeiro: José Olympio, 1942. p. 105. 
Este contato com José Ricardo, Fróis vincula-se ao elenco e passa durante três anos representando revistas, mágicas, operetas e zarzuelas. Um aspecto interessante é a logo vinculação deste ator ao teatro ligeiro o que, com certeza, proporcionou o desenvolvimento de um acervo interpretativo que será aprimorado durante os anos de atividade no Trianon.

Já em 1928, quatro anos antes da morte do ator e, segundo o memorialista, início de um período de decadência da sua popularidade, o mesmo apresenta-nos um modo de interpretar mais ajustado aos mecanismos da cena.

Nessa altura, Fróis firmava sua vasta experiência e imensa vocação num harmônico entendimento entre e expressão exterior e o sentimento interior. Sentia a própria segurança quando defrontava a platéia e a manobrava a seu bel prazer, sugestionando-a, prendendo-a aos encantamentos que se irradiavam de sua voz, do seu olhar, do seu sorriso, das suas inflexões ${ }^{13}$.

Na comemoração de 50 anos de morte de Leopoldo Fróis, o professor Alfredo Mesquita escreveu em diversos jornais paulistanos comentários acerca da performance atorial de Fróis:

Em Genro de muitas sogras, de Artur Azevedo, por exemplo, um dos seus maiores triunfos [...] tinha Fróis o papel central, é claro. O papel do impagável, assombroso Sacristão. Verdadeira obra-prima, a começar pela feiúra quase repelente, barriguinha empinada, pés espalhados, cabeleira ruiva, de franjinha, fazendo-lhe uma cabeçorra em forma de ovo, a expressão néscia às vezes, outras finória, o sorriso - também este do Fróes - parvo ou sibilino, a fala untuosa [...] verdadeiro anti-Fróis. (Depoimento de Alfredo Mesquita - Jornal da Tarde/SP, O2/10/1982).

"Fróis usava, de fato, seu charme, não se esquecendo, porém, de interpretar seus papéis com a máxima perfeição. Dizendo tudo isso pode parecer que dou uma impressão errada de Fróis, fazendo dela unicamente um ator de 'encanto pessoal'. Mas não. Não era somente isto, era isso também. Tal encanto, de fato, existia, não impedindo que fosse ele um verdadeiro grande ator [...]. É que ao lado ou acima, desses dons pessoais era intérprete da apuradíssima 'tarimba, de finissima sensibilidade, de aguda inteligência, carrada de espirito e mais fino e original, colaborando, se preciso fosse, com os autores nacionais vem sempre a altura do seu imenso talento de ator. (Alfredo Mesquita - A Gazeta/SP, 28/02/1982) 
Neste conjunto de depoimentos-memórias Alfredo Mesquita tece diversos comentários interessantes acerca da performance atorial de Fróis. Uma primeira observação se refere a percepção de um trabalho atorial que ia além da própria personalidade. A descrição de sua caracterização em Genro de muitas sogras se difere, e muito, da forma que a performance de Fróis é percebida. Aqui há indicações claras de um trabalho de "construção" de personagem tanto na caracterização quanto no aspecto gestual, ressaltando as qualidades expressivas do ator. Esta consideração nos direciona para uma percepção mais ampla do trabalho de Leopoldo Fróis, não somente calcado em 'qualidades pessoais de grande astro', mas também num trabalho atorial que contém acervos técnicos próprios, apreendidos no exercício do ofício.

Uma visão mais pontual do trabalho do ator no universo do teatro popular podemos verificar em dois trechos, redigidos em diferentes épocas, um primeiro de Alfredo Mesquita e o segundo de Viriato Correa.

também nessas pecinhas brasileiras colaborava com piadas, ditos, palavras que, repetidas inúmeras vezes, se gravavam na memória dos espectadores que saíam do teatro repetindo-as por toda a parte e que, adotadas por variadas classes sociais, integravam-se a própria vida da cidade. Assim Fróis usava e, talvez, abusava de truques não permitidos em teatro cultural, aceitáveis no teatro-digestivo, que era o dele. Nessas comédias de costumes - logo, tipicamente brasileiras, com pretensões a retratar a alta sociedade carioca que, aliás, tanto os autores como o próprio intérprete desconheciam e Fróis tinha suas mais peculiares e melhores interpretações". (Depoimento de Alfredo Mesquita - Jornal da Tarde/SP, 02/10/1982)

Em geral ia para a cena sem saber os papéis. Diziam que, quando ele os estudava, ninguém os fazia com mais perfeição. Não tive a felicidade de vê-lo em papel estudado, a não ser em Um beijo nas trevas, peça do gênero grand-guignol. Sempre titubeante, disfarçava o titubeio ora com cacos, ora com seu brilho natural. Ninguém, como ele, soube disfarçar a falta de estudo de um papel. Às vezes, por não saber uma linha das suas falas dava ao personagem defeitos de elocução. E conseguia excelentes resultados diante do público, que nele perdoava tudo. Como galã cômico, era um verdadeiro pupilo da platéia. Jovem simpático, elegante, dono de uma bela voz abaritonada de uma diç̧ão clara, destacava-se pelo desembaraço e pelos recursos cênicos que a vocação lhe dera. Tudo o que ele dizia, mesmo os mais chocantes disparates, provocava verdadeira trovoada de riso. Não representava sem enxertos, ora felizes, ora detestáveis. Foi ele, não o digo o inventor, mas o consagrador do caco. No seu tempo, todo o ator se julgava com o direito de enxertar ${ }^{14}$.

\footnotetext{
${ }^{14}$ MAGALHÃES JÚNIOR, Raimundo. As mil e uma vidas de Leopoldo Fróes.

Rio de Janeiro: Civilização Brasileira, 1966. pp. 45-46.
} 
Torna-se importante nestes documentos a identificação dos procedimentos interpretativos e suas relações com o modo de produção artística popular do teatro digestivo, o qual possuía características próprias: um sistema de teatro por sessões, rodízio constantes dos espetáculos em cartaz, produção dramaturgia contínua e baseada em estruturas móveis.

As companhias estavam organizadas, na sua maioria, por atoresempresários que conduziam tanto a cena - na função dos primeiros atores - quanto à administração da companhia. Fróis foi um dos mais importantes atores-empresários do seu tempo, participou de diversas companhias e constituiu a Companhia Leopoldo Fróis, onde era o primeiro-ator. Nela a atriz Dulcina de Moraes iniciou sua carreira artística.

Tais companhias eram estruturadas a partir do mecanismo/recurso de variar o elenco, ou seja, uma gama grande de atores eram acionados a cada montagem, permitindo uma intensa movimentação dos atores a procura de um elenco onde pudessem se integrar Esta integração, muitas vezes se dava pelo encaixe do ator - tipo físico - ao personagem-tipo necessário.

A escrita dramatúrgica e cênica destes espetáculos eram calcadas na tipificação dos papéis, onde os atores se encaixariam, segundo seu perfil, ocupando uma determinada função na peça. Esta estrutura de personagens, comuns nas comédias de costumes, constituía o elo de ligação entre o universo dramático e o retrato social da cidade.

Seguindo este raciocínio e verificando a informação contida nos depoimentos, podemos apontar que Leopoldo Fróis aproveitou as possibilidades oferecidas pela dramaturgia - e toda sua estrutura para o exercício atorial no qual sua 'personalidade' fosse desenvolvida articulando-a a procedimentos de elaboração técnica, o que pressuponha um exímio domínio da cena.

Segundo os documentos nosso ator era um excelente criador de cacos, o que muitas vezes garantia a adaptabilidade dos textos ao público presente nos espetáculos. Essa improvisação está ligada ao conhecimento que cada um dos atores tem de seus tipos. Nesta perspectiva, podemos apontar para um modelo de formação atorial que, ao ser realizar no exercício constante de uma tipologia dramatúrgica que possibilitava a participação do ator como um co-autor, na medida em que garantia uma efetiva participação do mesmo na sua realização/materialização cênica vinculada a este modo de produção teatral popular. 


\section{Referências bibliográficas}

CHIARADIA, Maria Filomena V. A Companhia de Revistas e Burletas do Teatro São José: a menina-dos-olhos de Paschoal Segreto. Dissertação (Mestrado em Teatro). CLA-UNIRIO, Rio de Janeiro, 1997.

MAGALDI, Sábato. Panorama do Teatro Brasileiro. São Paulo: Global, 1997.

MAGALHÃES JÚNIOR, Raimundo. As mil e uma vidas de Leopoldo Fróes. Rio de Janeiro: Civilização Brasileira, 1966.

RABETTI, Beti. Subsídios para a história do ator no Brasil: pontuações em torno do lugar ocupado pelo modo de interpretar de Dulcina de Moraes entre tradição popular e projeto moderno. Revista do LUME, n. O2, UNICAMP/ COCEN. Campinas, 1999.

. História do teatro "popular" no Brasil: Gastão Tojeiro entre autoria artística e práticas sociais do teatro ligeiro. Revista do LUME, n. 06, UNICAMP/COCEN. Campinas, 2005.

. O "homem de teatro" Armando Gonzaga: entre comédias de costume e um costume de fazer comédias. OuvirOuver, n. 01, 2005. DEMAC/UFU. Uberlândia, 2005.

TOJEIRO, Gastão. O Simpático Jeremias. In: Revista de Teatro da SBAT. Rio de Janeiro, 1966 (n. 350).

. O Café do Felisberto ou A conferência do garçon. Rio de Janeiro: Papelaria e Tipografia Coelho, 1941.

TOMÉ, Alfredo. Leopoldo Fróis e o teatro brasileiro. Rio de Janeiro: José Olympio, 1942.

TROTTA, Rosyane. O teatro brasileiro: décadas de 1920 - 30. In: BRANDÃO, Tânia (org.) O Teatro através da história. Rio de Janeiro: CCBB/ Entourage, 1994.

VELloso, Mônica Pimenta. A cultura das ruas no Rio de Janeiro (1900-30). Mediações, linguagens e espaços. Rio de Janeiro: Casa de Rui Barbosa, 2004. 